\title{
Practice-oriented Vocational Education Teaching Reform of Mechatronic Specialty
}

\author{
Yao-wu SHEN ${ }^{1, a}$, Jin-dong YU ${ }^{2, ~ *}$, Fa-yun DENG ${ }^{1, b}$ \\ 1. Guangzhou Nanyang Polytechnic, Guangzhou 510925, China \\ ${ }^{2}$ Guangdong Construction Polytechnic, Guangzhou 510440, China \\ a306908510@qq.com, ${ }^{b} 1737425042 @ q q . c o m$ \\ *Corresponding author: yujindong@gdcvi.net
}

Keywords: Teaching reform, mechatronic, practice-oriented.

\begin{abstract}
The next ten years are the key period of China's economy because of going from the mass manufacturing country to the strong one. The key of successfully transforming and upgrading with healthy development is to improve the quality of employee. The basic solution is to carry out the practice-oriented teaching reform of mechatronic specialty. Firstly, stems from the need of high quality and skilled talent at the forefront, analyses of defects in the set of curriculum, teaching staff and the skill training base are made. Then, the reform plan is put forward, which includes constructing professional curriculum system originated from occupational competency, developing general cognitive course serving for the professional quality, designing the three progressive levels of practice training module and the matched teaching materials, cultivating double qualification teaching staff and the constructing win-win skill training base by production and education fusion.
\end{abstract}

\section{Introduction}

Mechatronic technology is one of the core technologies in manufacturing industry, which is the basis of manufacturing being automation, flexibility, integration, network and intelligence. The China State Council formally issued the Made in China 2025 Strategy on May 8, 2015. That means by 2025 there will be an outcoming with a substantial increase in the overall quality of manufacturing industry, a significantly enhanced innovation capability, a significant increase of total labor productivity rate, as well as the fusion of industrialization and information stepping on a new level. In order to adapt to the new round of technological and industrial revolution, to meet the applied and innovative skilled talent training for the manufacturing production line, it is admit no delay to carry out teaching reform of mechatronic specialty in vocational college.

\section{Current Teaching Situation of the Electromechanical in Higher Vocational College}

\subsection{Situation of Course Construction}

2.1.1 The content of the course is out of line with the demand of occupational ability

Now, it is difficult to cultivate the core competence of professional position for students in the course of mechatronic specialty in higher vocational colleges. The reason is because the teacher being as the main body of developing curriculum criterion. Thus there will inevitably exists the phenomenon of emphasizing theory rather than practice, as well as neglecting the correlation of curriculum content and the ability of professional position. Lack of taking the professional post ability demand as the starting point to formulate the curriculum content leads to the weak competency of searching for occupation after graduation.

2.1.2 The curriculum construction lacks the unique of Higher Vocational Education

The vocational education is unique from others. There is a close connection between the student's college learning and the enterprise training. Therefore, the integration of theoretical knowledge and practical training is the key for the curriculum reform. Based on the position ability, combination of 
theory and practice, writing practice oriented teaching materials by integration of learning and doing is worthy.

Because most teachers lack of practical experience in the production line of enterprises, curriculum development without participation of first-line technical staff inevitably cause the curriculum reform none of deep enough. The curriculum is not closely related with the enterprise practice, which causes the student to study on theoretical knowledge and escape from the need of reality, even simple but no useful skills.

As to the construction of teaching materials, the reduction or compression version of undergraduate teaching materials is used in mechatronic specialty of vocational education. Even some colleges organize teachers to write school-based teaching materials, but due to the lack of participation of enterprise technical personnel, the content of the teaching material can' t match with the abilities needed by the professional post. In a word current teaching materials can' $t$ deal with the relationship between theory and practice, knowledge and skills, which makes teaching-learning-doing integration model reform is difficult to carry out.

\subsection{Situation of Teachers}

\subsubsection{Insufficient quantity}

Increasing enrollment for several years caused a large gap of teacher in the mechatronic, ratio of teacher and student is not reasonable. The reason lies in multi aspects, such as the lower acceptance of high vocational colleges in social and the limited developing space, thus talents possessing both solid theoretical level and rich practical experience or skilled craftsmen are very scarce human resource between high vocational colleges, moreover whose salaries provided by vocational college are much more lower than those of enterprise.

\subsubsection{Irrational structure}

(1) There are more young teachers in teaching body which results the structure of age is not reasonable. Because of the high quality teachers is difficult to be recruited, many colleges reduces recruitment standards, all of these let a graduate student even if without teaching and business experience can be hired, as long as the one majors in the right need specialty. Eventually young teachers have more influence on the overall teaching quality level.

(2) The on-going conferring academic title system works well to a certain degree in motivating and improving the quality of education. Nowadays, the title structure is not reasonable, the young primary titles and the older advanced ones account for high proportion of the teaching body. The phenomenon of teachers' polarization and middle fault is seriously restricting the improvement of teaching quality. It can be seen from the age and professional titles structure of teachers that on the one hand there are more young teachers, on the other hand the introduction of high professional titles also doesn' $t$ consider whether they have business practice, regardless of age, or even if the knowledge structure meet with the requirement of specialty.

(3) The current teaching body of vocational education basically can be divided into theoretical teacher and skill training director. While the structure of knowledge and vocational competency is irrational because there are more theoretical teachers and less training director, especially the ratio of double qualification teacher is too low. To investigate its reason, many colleges put importance neither on the cooperation between the school and enterprise nor the cultivation of teachers' professional skills as well as supporting for construction of production, learning and research.

\subsubsection{Vocational practice skill is not strong}

Influenced by the traditional concept of elite education lots of teachers ignore the cultivation of polybasic talents, who prefer to the teaching of theoretical knowledge rather than the practical one. Without practical experience teachers can' $\mathrm{t}$ to talk about proficient skills. The teacher with vocational qualification certification or true skill who could be called skilled craftsmen and genuine knowledge is really shortened. 


\subsection{Situation of Training Base}

\subsubsection{Objectives of School and Enterprise are Different}

The basic function of the mechatronic professional training base is executing the professional practical teaching and vocational skills training to cultivate and improve students' practical ability. Although purpose of the base is to cultivate talents for enterprises, schools and governments are highly motivated while the enthusiasm of enterprises is obviously poor during constructing process. The reason is that the college sets the goal of talents' training quality, and the goal of the enterprise is to pursue interests. The differences between the targets of the two sides cause the cooperation among them become a mere formality without reaching a win-win situation. Thus the training base can' t play a real role.

\subsubsection{Teaching and Practice Come Apart}

Mechatronic professional school training base undertake professional training teaching segment of which the training courses should be able to meet the requirements of training students' practical skills and vocational quality. But most teachers aren' t of the "double qualification" teachers who are lacking of practical experience to prepare training materials or guidance books with targeted practical and suitable for higher vocational college students' cognitive level. The difference between the teaching course and the training content is very big, so college can' t provide training courses to meet the needs of students nor the training needs of enterprises.

\subsubsection{Contradictions of Training base Construction and Use}

The training base of mechatronic is confronted with the problems of construction and utilization. One the one hand training base construction requires a large amount of funds for the acquisition of instruments or equipment while lack of funds restricts the construction of training base. On the other hand, due to lack of planning, established training base can' t meet the needs of practical teaching, the rate of usage is not high, which results in idle waste of resources. The contradiction between the shortage of resources and the coexistence of idle waste make the construction of the training base being in a dilemma. Lacking of funds the training base in school can' $t$ form a certain scale, meanwhile the training base out of school is not willing to accept more students.

\section{Practice-oriented Teaching Reform of Mechatronic Specialty in Vocational Education}

\subsection{Curriculum Reform}

3.1.1 Construct the Professional Curriculum System According the Core Competence of Occupation

Constructing the professional curriculum system according to the core competence of vocational occupation takes the mode of Post-Ability-Course. In the process of course constructing the school should organize experts, teachers, technical personnel from enterprise to start from the point of occupation ability requirements, analysis the typical occupational positions in industry chain, and by focusing on the professional core positions to determine the core competencies. Centering on the core competence could the Practice Oriented Mechatronic Specialty Curriculum System be reasonably designed. Therefore, the analysis of the core competence of the occupation is the designing logical starting point of the practice oriented curriculum system for higher vocational education[1].

\subsubsection{Develop General Cognitive Course Serving for the Professional Quality}

The setting of general cognitive courses should reflect the purpose of serving and improving students' professional quality. Public elective courses should serve for improving students' humanities, art and professional quality. The setting of general cognitive course is not aimed at a professional post, but it is useful for cultivating the general ability and the professional ability which will make the competitive ability for individual development and promote personal overall development. Thus the purpose of offering general courses, on the one hand, is serving to enhance the students' professional quality, on the other hand, to serve for better study of professional courses.

\subsubsection{Design Three Progressive Levels of Practice Training Module}

According to the cognitive law of students, the three progressive levels of practice teaching module should be design as one system. Three progressive levels of practice teaching refers to the 
level of doing by learning, the level of learning by doing and the level of learning by exploring, which help students master the knowledge and technical skills needed for professional positions[2].

The level of doing by learning is to complete the technical knowledge acquisition and the training of a single skill. This teaching level is designed to organize various points of knowledge and skills into the professional courses. The knowledge and skills points are integrated into one teaching mode of teaching, learning and doing.

The level of learning by doing is to complete the comprehensive project training. Before the end of each professional course, the designed comprehensive training program should connect the skill points and knowledge points of the course into ability links to let students going into training. The comprehensive training program usually requires the teacher to transformation some actual case coming from the enterprise into a teaching project. Through this teaching mode of learning by doing could students complete building the comprehensive ability, which are not only processes of consolidating knowledge points of professional courses but also of promoting skills and cognitive into comprehensive ability.

The level of learning by exploring is the process of an independent completion of the graduate project. The teacher provides the application subject to instruct students' graduate project. The project generally comes from the enterprise real research and development project. This graduate project connects the links of knowledge and skill formed in major professional courses into a competitive surface. Namely through the teaching mode of learning by exploring, the competitive ability consisting of application, innovation and innovation is developed for students.

\subsubsection{Develop Practice Oriented Teaching Materials}

Teaching material construction is the basic step to improve the quality of teaching, which is also the principal foothold of practice oriented curriculum reform. Teaching reform results are solidified into teaching materials, which are also the important carrier for the school to continually promote the construction of curriculum. Practice oriented teaching material of mechatronic in higher vocational colleges should aim at cultivating students' practical operation skills meanwhile much more attention should be paid to the fuse of professional knowledge and skills training. By internalizing the knowledge and skills into contents of cultivating students' core professional post competence, the teaching material should strive to embody the professional characteristics and the course characteristic. And the teaching material should also satisfy the teaching mode of doing by learning and learning by doing. During the process of developing teaching material, in order to assure the teaching material content docking with the production practice, apart from requirement of teachers' teaching and practical ability, it is necessary to encourage frontline professional or technical persons in industry enterprise to implement the production practical experience to participate in it[3].

\subsection{Cultivate Double Qualification Teaching Staff}

\subsubsection{Cling Importing Quantity and Insuring Quality}

The primary task of the construction of the teaching staff is to import a certain number of teachers. The concrete number of teachers can be set based on the professional developing plan and in accordance with the proportion of teachers and students standard of talent cultivating quality evaluation system. In order to insure the quality of teacher there are three approaches. The first approach of importing teachers is to select graduates from the university with practical experience of production. The second one is to introduce teachers or researchers with highly educated or professional titles from the other university or Institute. The last one is to absorb skilled craftsmen with certain theoretical level and practical skills from enterprises.

\subsubsection{Strengthen Training and Improving Quality}

Strengthen on-the-job teachers' education and training is vital to enhance their professional operating quality unceasingly. There are two measures to be adopted. The first measure is to enhance the academic degree or improve the theoretical level by continue learning because the current situation of teaching body shows that young teachers are relatively owner with low degree or theoretical level. Furthermore the continuous emergence of new theories and new technologies makes it necessary for teacher to take part in continues learning and training. The second one is to 
strengthen the training of professional teachers' practical ability, of which the college should arrange on-the-job professional teachers into the business line or related training institutions to accept training[4].

\subsubsection{Professional Matching with a Mixture of Full-time and Part-time Teachers}

The key to improving the quality of teaching is the relative stability of the teaching staff. Professional counterparts of the teachers can be imported, trained, hired according to the specific professional characteristics, professional developing planning. According to the classification of curriculum group, at least three full-time backbone teachers are needed for each group and the rest needed teachers can be solved by employing part-time teachers. Practice oriented part-time teacher resources is relatively small thus skillful craftsmen can be hired mainly from the enterprise production line.

\subsection{Construct Win-Win Skill Training Base by Production and Education Fusion}

3.3.1 Change the Cooperative Belief to Achieve School and Enterprise Mutual Benefit and Win-Win

Mechatronic training base should have advanced, complete sets of equipment and double qualification teachers. Only this condition is met can the training base provide external technical service and make its own resources to be effectively used. In the practical course, only the exporting technical service for the enterprise bring benefits or skilled personnel can the college call on enterprises to invest in the construction of training base and upgrade hardware facilities. Similarly, the enterprises are also only convinced that the skill type talented person is the basic propelling force for their development and the only core competitiveness element, and then they will strengthen cooperation with the school to establish a more comprehensive training base[5].

\subsubsection{Strengthen Planning and Optimizing Configuration of Resources}

Different ways by which training base take for construction and management will result in different level of benefits and services. College should try to improve the configuration of training base with equipment and professional teachers. At the same time, schools should comprehensively weigh the resources of all aspects and make an overall planning to arrange train teaching resources to be fully utilized to achieve the optimal allocation and share.

\subsubsection{Form Scientific Management Mode to Improve Utilization Efficiency}

Training base construction funds are short and professional laboratory usage is not high, thus there are coexistence phenomenon of idle and resources shortage. For the idle questions, the reasons should be analyzed and means should be controlled to improve the construction target. For the construction funding problems, we should expand the cooperation between schools and enterprises, through factory in school or school in factory cooperating mode, the purpose of training can be achieved by making full use of enterprise resources.

\section{Conclusion}

The industry supported by mechatronic is the manufacturing industry which is called the main body of the national economy. Manufacturing industry has been a strong driving force of China's economic development. The next few years is the critical period of transformation and upgrading of China's manufacturing industry from manufacturing big country to manufacturing strong country. The sustained and healthy development of the manufacturing industry is still the main driving force for the economic development of our country. Only by continuously deepening teaching reform, can we cultivate high-quality skilled personnel to meet the needs of enterprises and social development under the new normal.

\section{Acknowledgments}

The paper is the result of the teaching reform of higher vocational education reform in Guangdong province in the year of 2014, which is based on practice - oriented teaching reform of mechatronic in vocational colleges (201401326). It's also the result of 2015 annual Guangdong province education institute of education research topic "university-enterprise cooperation training center to promote 
transformation and upgrading of manufacturing" (GDJY - 2015 - B - b030) research. Meanwhile it' s one of the 2016 annual didactic researching projects of high vocational education in Germany supported by China State Council of Education Department.

\section{References}

[1] Jin-chang DING, Reformation and innovation of Practice-oriented Curriculum in Vocational Education, J. Research in Higher Education of Engineering. 1 (2015) 119-124.

[2] Tian-tian HU,Wang Hongchen,Establishment of Practical an Innovative Personnel Training System in Higher Vocational College, J .Research and Exploration in Laboratory, 6 (2011) 205-217.

[3] Ying-hua WANG, The Thought of Cultivating Innovating Talents on the Direction of Employment in Advanced Vocational Colleges, J. Journal of Huanggang Polytechnic. 1 (2008) 22-24.

[4] Xiao-yue HU, Ning FENG, Teaching Reform of the Practice-oriented Electrom echanical Integration Specialty in Higher Vocational School, J. Vocational technical education. 32 (2006) 20-22.

[5] Yong-hao JIANG, The building research of "Double” teaching team in Mechatronics Technology Specialty in Higher vocational colleges, J. Journal of Huanggang Polytechnic. 1 (2013) 55-57. 